\title{
Modeling, Simulation and Analysis of Bearing Voltage and Bearing Current in PWM Multilevel Inverter Fed Induction Motor with Different HP Ratings
}

\author{
Sunitha P M ${ }^{1}$, Dr. Basavaraja Banakara ${ }^{2}$, Sharana Reddy ${ }^{3}$ \\ PG Student, Dept of Electrical Engineering, University BDT College of Engg, Davangere, India ${ }^{1}$ \\ Professor, Dept of Electrical Engineering, University BDT College of Engg, Davangere, India ${ }^{2}$ \\ Associate Professor, Dept of Electrical Engineering, Ballari institute of Technology and Management, Ballari, India ${ }^{3}$
}

\begin{abstract}
Adjustable Speed Drives (ASDs) are extensively used in commercial and industrial heating, ventilation, air conditioning and refrigeration (HVAC/R) equipment's because of many advantages in control and energy savings. The ASDs use PWM inverter with high speed switching devices such as Insulated Gate Bipolar Transistors (IGBTs) generates the common mode voltage $\left(V_{c m}\right)$. This $V_{c m}$ causes the bearing voltage $\left(V_{b}\right)$, which leads to premature bearing failure.In some industrial applications the PWM inverters and the motors are located separately thus requiring long motor cable. Which contributes over voltage and higher $\mathrm{V}_{\mathrm{cm}}$ at the motor terminal due to the voltage reflection phenomenon. Higher the common mode voltage results in higher induced $\mathrm{V}_{\mathrm{b}}$. This paper presents modeling, simulation and analysis of bearing current, bearing voltage in PWM multilevel inverter fed induction motor of 5HP and 10HP Motors and THD Analysis of PWM MLI fed induction motor without long cable is done. Simulation is carried out using MATLAB Simulink.
\end{abstract}

Keywords: Adjustable speed drives (ASDs), Bearing voltage, Bearing voltage Ratio (BVR), Common mode voltage, Voltage reflection phenomena, Multilevel Inverter.

\section{INTRODUCTION}

Theoccurrence of bearing voltage and bearing currents in an Induction Motor (IM) has been known for decades. Asymmetric flux distribution is the basis that causes bearing currents inside the IM [1]. It has been productively solved using modern motor design and manufacturing methods. In many new and retrofit industrial applications the PWM inverters and motors must be at separate locations thus requiring long motor cable, which contributes over voltage at the motor terminal due to the voltage reflection phenomenon.

In PWM inverter with IGBT operate at switching frequencies of 2 to $20 \mathrm{kHz}$ and a rise time of $0.1 \mu$ sec with voltage rise of $6000 \mathrm{~V} / \mu \mathrm{sec}$ for $400 \mathrm{~V}$ system. The high $\mathrm{dv} / \mathrm{dt}$ has adverse effects on bearing damage caused by bearing currents due to common mode voltage $\left(\mathrm{V}_{\mathrm{cm}}\right)$. $\mathrm{V}_{\mathrm{cm}}$ increases in the presence of long motor cable $(>20$ feet $)$ [2][3].

Electric Discharge Machining (EDM) bearing current: The bearing voltage $\left(\mathrm{V}_{\mathrm{b}}\right)$ mirrors common mode voltage $\left(\mathrm{V}_{\mathrm{cm}}\right)$. When $\mathrm{V}_{\mathrm{b}}$ exceeds dielectric strength of lubricating oil film $(15 \mathrm{Vpk} / \mu \mathrm{m})$, oil film breaks down , thereby causing the EDM current pulses and results in bearing failure. The bearing currents cause premature bearing failure within 1-6 months of installation [4].

The experimental measurement of the $\mathrm{V}_{\mathrm{cm}} \mathrm{V}_{\mathrm{b}}$ and bearing current under space vector modulation scheme for five level neutral point clamp inverter fed induction motor was carried out. The five level inverter generates less $V_{c m}$ and $V_{b}$ compared to the 2-level and 3-level [5].

The magnitude of the $\mathrm{V}_{\mathrm{b}}$ and the $\mathrm{I}_{\mathrm{b}}$ produced by the medium voltage 3-level NPC PWM VSI drive system is less than 2level inverter. In addition to that, general approaches in solving the $\mathrm{V}_{\mathrm{b}}$ and $\mathrm{I}_{\mathrm{b}}$ problems were discussed [6]. The effect of motor cable length, rise time and motor HP ratings on the over voltage were discussed in 2-level PWM ASD. As the motor cable length increases over voltage magnitude increases. The paper didn't address influence of motor cable length on the magnitude of $\mathrm{V}_{\mathrm{cm}}, \mathrm{V}_{\mathrm{b}}$ and $\mathrm{I}_{\mathrm{b}}$ [7] 


\section{IJIREEICE \\ International Journal of Innovative Research in Electrical, Electronics, Instrumentation and Control Engineering \\ ISO 3297:2007 Certified \\ Vol. 5, Issue 4, April 2017}

A passive R-C filter installed at the motor side is an effective method for restraining the over voltage and bearing current in a PWM inverter fed induction motor with long cable. The work carried out using only basic 2-level inverter [8]. Three filter topologies such as, RLC filter at the motor terminals, RLC filter at the inverter output terminals and reactor filter were discussed and compared. The RLC filter at the inverter output is the most effective solution among the three topologies [9]. Simulation analysis of $\mathrm{V}_{\mathrm{cm}}$ and $\mathrm{V}_{\mathrm{b}}$ in 2-level and 3-level PWM ASD with long cable is presented in this paper the work is extended to 5-level PWM ASD [10].

This paper is organized as follows: section. I give introduction. Section. II deals with common mode voltage and bearing voltage. Section. III deals with voltage reflection Analysis. Section. IV deals with Simulink modeling. results and discussion are presented in section V. Section. VI is conclusion followed by references and bibliography.

\section{COMMON MODE VOLTAGE AND BEARING VOLTAGE}

In PWM inverter fed motor, an average voltage at a neutral point w.r.t ground is non zero and is known as common mode voltage, it is given by the equation (1)

$$
V_{c m}=\frac{\left[V_{a n}+V_{b n}+V_{c n}\right]}{3}
$$

In the above equation $\mathrm{V}_{\mathrm{an}}, \mathrm{V}_{\mathrm{bn}}$ and $\mathrm{V}_{\mathrm{cn}}$ are the phase voltages. The bearing voltage $\left(\mathrm{V}_{\mathrm{b}}\right)$ is given by equation (2)[3] [4].

$$
V_{b}=\frac{C_{s r}}{C_{s r}+C_{r f}+C_{b}} V_{c m}
$$

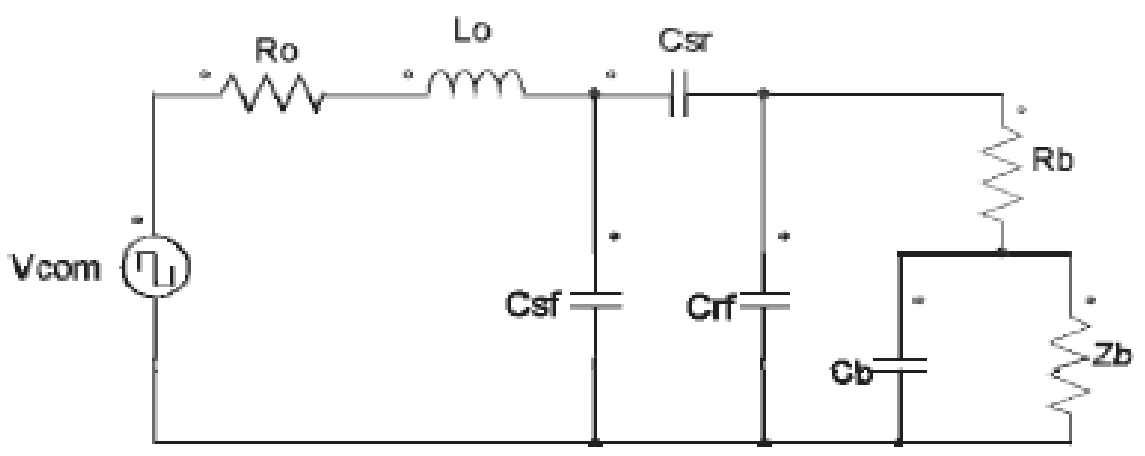

Fig.1. Common mode equivalent circuit

Where, $\mathrm{C}_{\mathrm{sr}}$ is capacitance between stator winding and rotor, $\mathrm{C}_{\mathrm{rf}} \mathrm{is}$ capacitance between stator frame and rotor (air gap capacitor) and $\mathrm{C}_{\mathrm{b}}$ is bearing capacitance.

\section{VOLTAGE REFLECTION ANALYSIS}

The PWM pulses travels from an inverter to the motor terminal at approximately half the speed of the light (150 to $200 \mathrm{mt} / \mu \mathrm{sec}$ ), if the pulse takes longer than $1 / 3^{\text {rd }}$ of output pulse rise time, then a full reflection occurs at the motor terminals and the pulse amplitude will be approximately doubled in the presence of long motor cable. Over voltage at the motor terminal depends on rise time of the PWM pulses, the cable length and the impedance mismatch between the power cable and motor. The impedance of smaller motors is dominated by winding inductance, thus in comparison with the low surge impedance of the cable the motor impedance is high [7].

\section{SIMULINK MODELING}

Fig.2 shows MATLAB Simulink model of 5-level PWM ASD. High frequency induction motor modeling is presented as in [11]. High frequency cable modeling is carried out as in [12]. Three and five level diode clamped multilevel inverter fed induction motor drive modeling is implemented using MATLAB Simulink. Sine-triangle PWM technique is used with switching frequency $2 \mathrm{KHZ}$. 


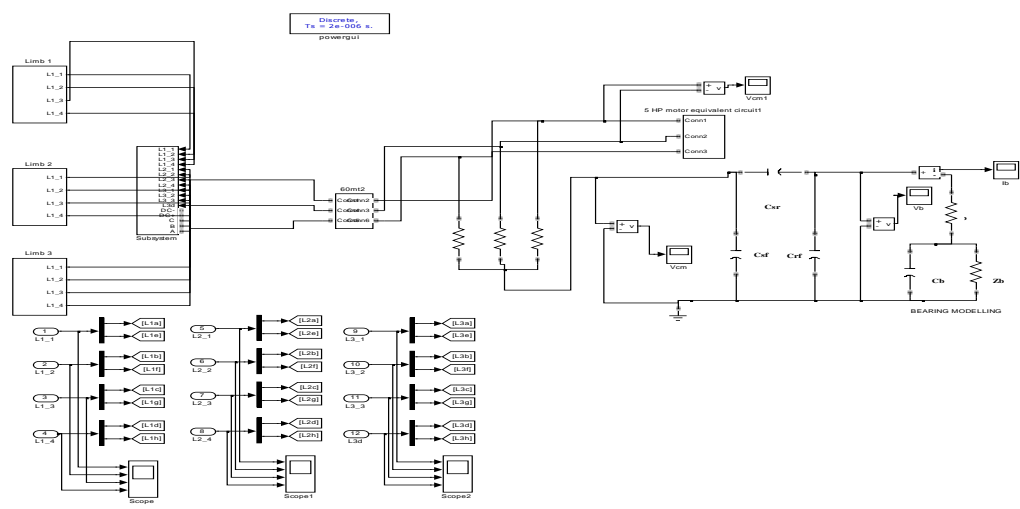

Fig. 2 Simulink model of 5 levels PWM inverter fed induction motor.

\section{RESULTS AND DISCUSSION}

A. Three level

Figs3(a)-3(c) and figs.4(a)-4(c) show the simulation results of $\mathrm{V}_{\mathrm{cm}}, \mathrm{V}_{\mathrm{b}}$ andIb of 3-level PWM inverter fed induction motor for $5 \mathrm{HP}$ and $10 \mathrm{HP}$ without long cable respectively.
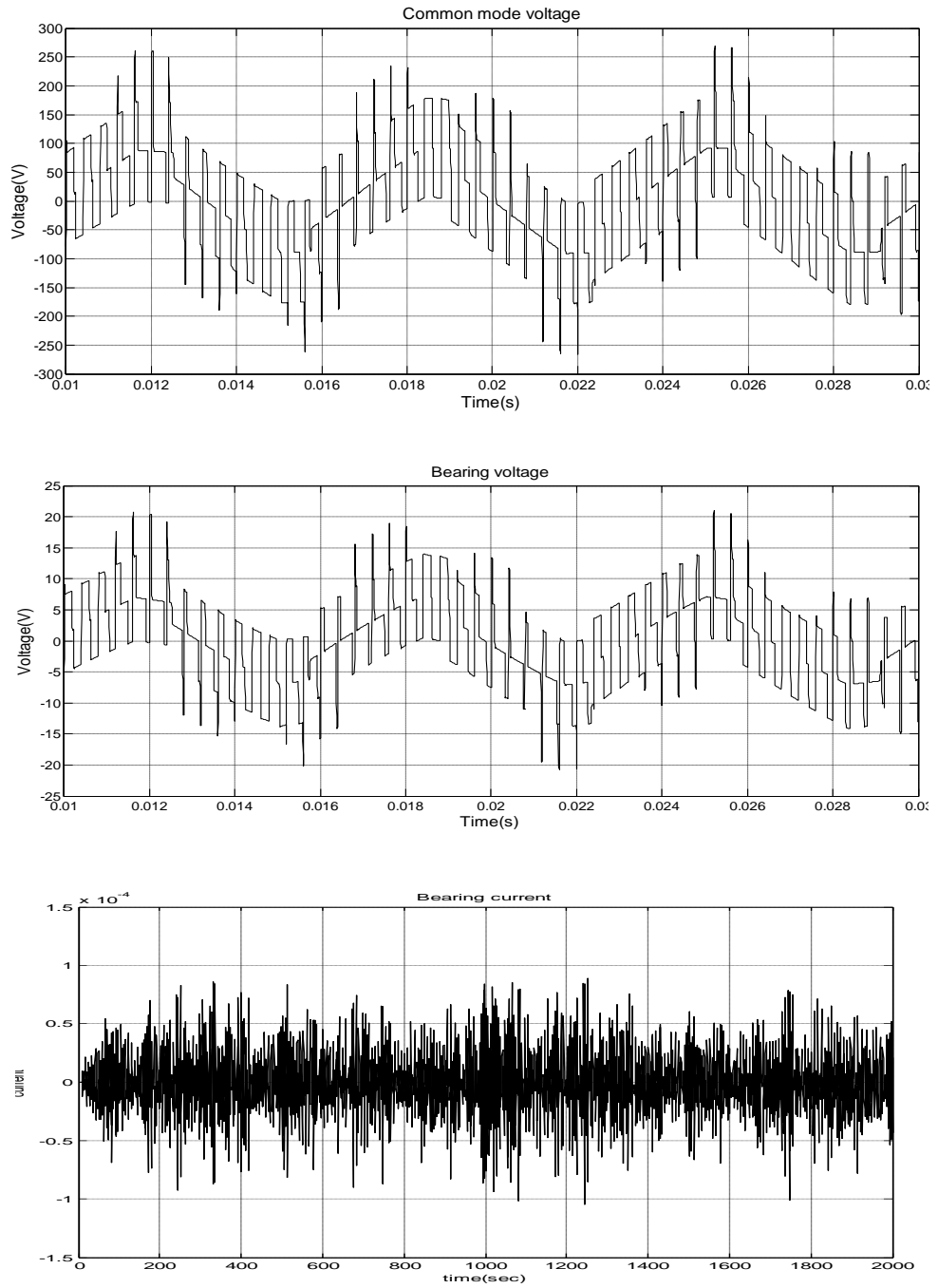

Fig.3 Simulation results of a) common mode voltage b) bearing voltage c) Bearing current without long cable (3-Level, 5HP) 


\section{International Journal of Innovative Research in} Electrical, Electronics, Instrumentation and Control Engineering

ISO 3297:2007 Certified

Vol. 5, Issue 4, April 2017
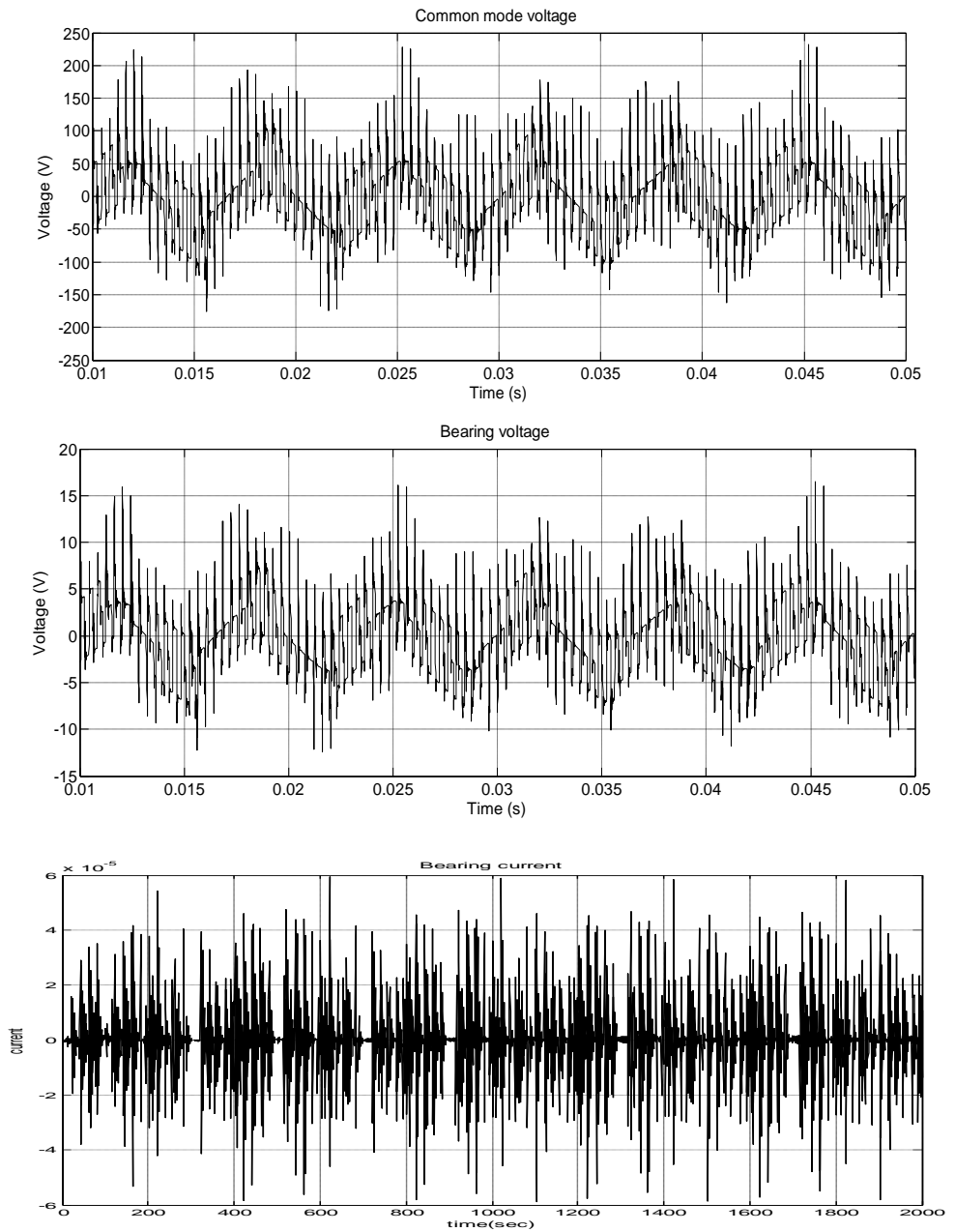

Fig.4 Simulation results of a) common mode voltage b) bearing voltage c) bearing current without long cable (3-Level, 10HP)

\section{TABLE-I SIMULATION RESULTS OF 5-LEVEL, 5HP AND 10HP MOTORS}

\begin{tabular}{|l|l|l|}
\hline \multirow{2}{*}{ Parameters } & 3-level, 5HP & 3-level, 10HP \\
\cline { 2 - 3 } & \multicolumn{2}{|c|}{ Without long cable } \\
\hline Common mode voltage (V) & 275 & 225 \\
\hline Bearing voltage (V) & 21 & 16 \\
\hline Bearing current (mA) & 0.08 & 0.05 \\
\hline BVR (\%) & 7.6 & 7.1 \\
\hline
\end{tabular}

\section{B. Five level}

Figs5(a)-5(c) and figs.6(a)-6(c) show the simulation results of $\mathrm{V}_{\mathrm{cm}}, \mathrm{V}_{\mathrm{b}}$ and $\mathrm{I}_{\mathrm{b}}$ of 5-level for diode clamped PWM inverter fed induction motor for 5HPand 10HP without long cable respectively.

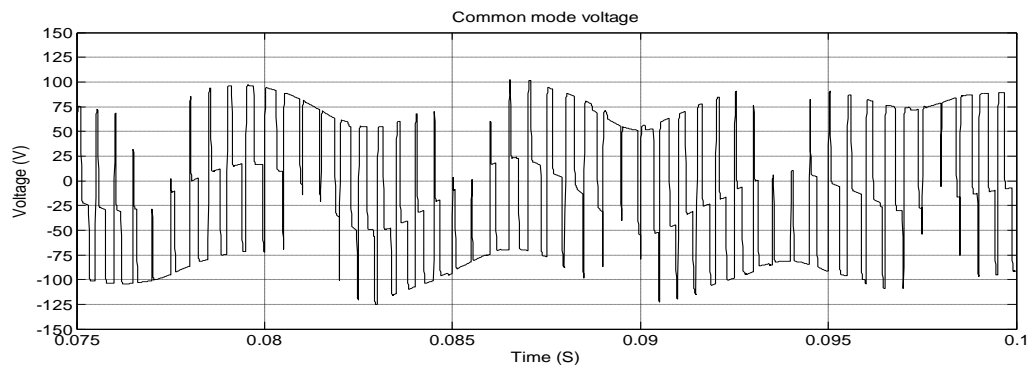


International Journal of Innovative Research in Electrical, Electronics, Instrumentation and Control Engineering

ISO 3297:2007 Certified

Vol. 5, Issue 4, April 2017
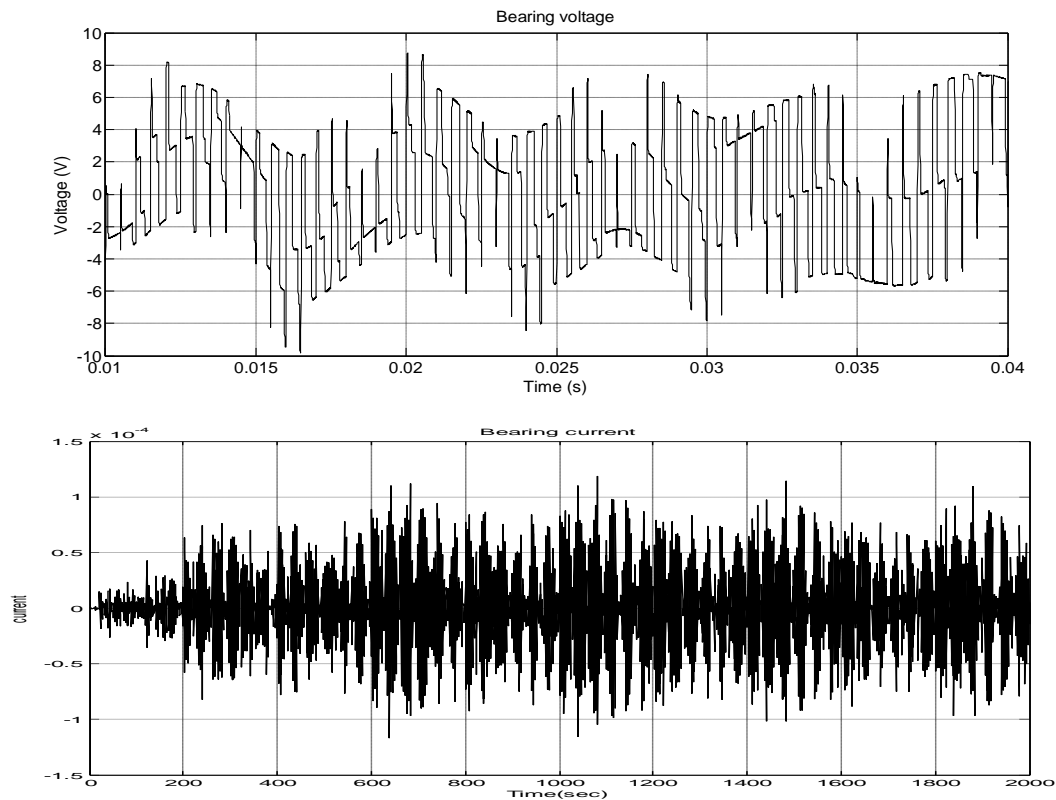

Fig.5 Simulation results of a) common mode voltage b) bearing voltage c) bearing current without long cable (5-Level, 5HP)
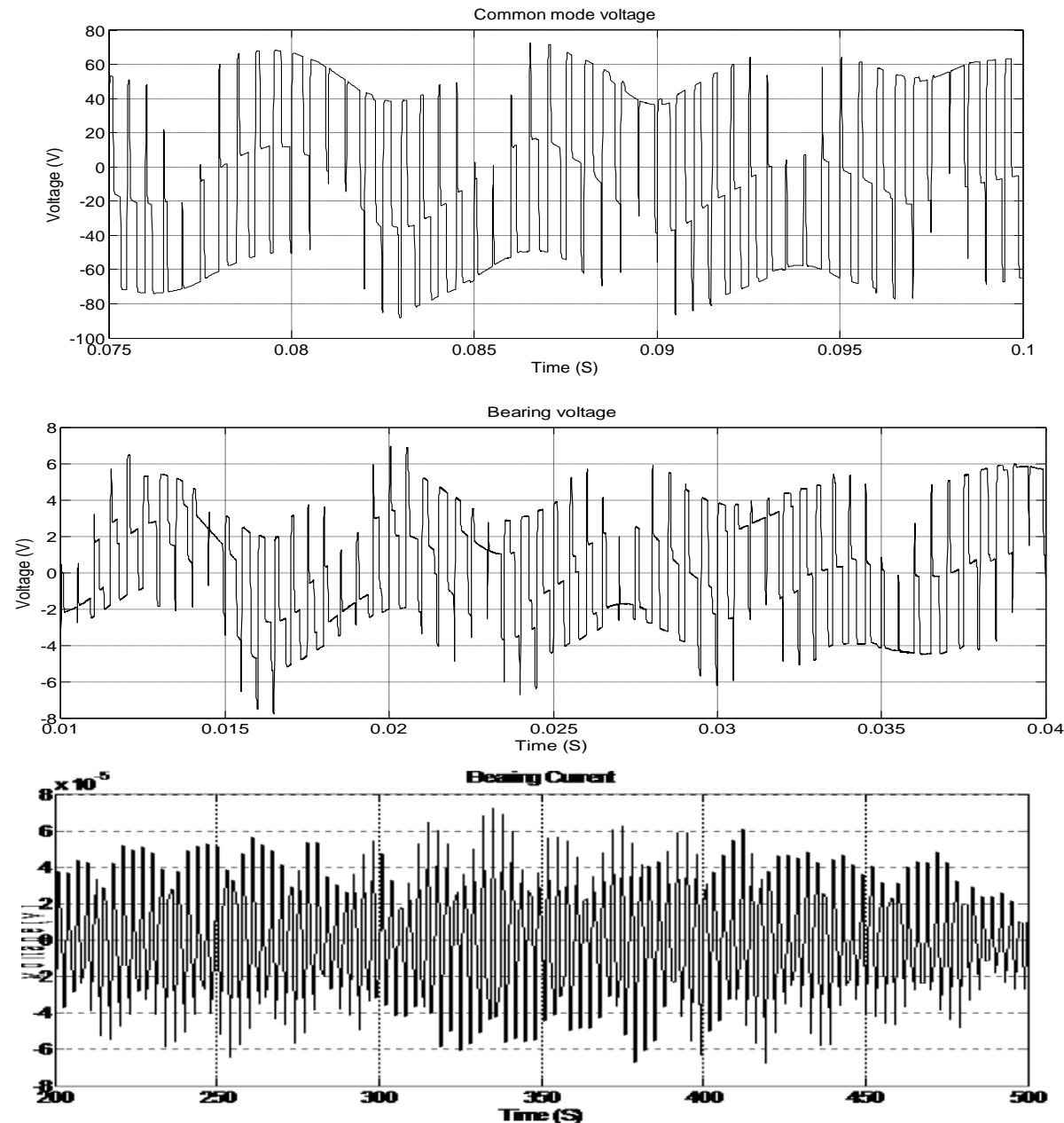

Fig.6 Simulation results of a) common mode voltage b) bearing voltage c) bearing current without long cable (5-Level, $10 \mathrm{HP}$ ) 
Vol. 5, Issue 4, April 2017

Table. II gives the simulation results of 5-level, 5HP and 10HP induction motors. It is observed that the increase in the values of $\mathrm{V}_{\mathrm{cm}}, \mathrm{V}_{\mathrm{b}}$ and $\mathrm{I}_{\mathrm{b}}$ is less for $10 \mathrm{HP}$ motor compared to $5 \mathrm{HP}$ motor, due to low impedance of 10HP motor compared to 5HP hence, voltage reflection will be less.

TABLE-II SIMULATION RESULTS OF 5-LEVEL, 5HP AND 10HP MOTORS

\begin{tabular}{|c|c|c|}
\hline \multirow[t]{2}{*}{ Parameters } & 5-level, 5HP & 5-level, 10HP \\
\hline & \multicolumn{2}{|c|}{ Without long cable } \\
\hline Common mode voltage (V) & 102 & 71 \\
\hline Bearing voltage (V) & 8.7 & 6.9 \\
\hline Bearing current (mA) & 0.125 & 0.066 \\
\hline BVR (\%) & 8.0 & 9 \\
\hline
\end{tabular}

It is observed from figs3 (a)-3(c), 4(a)-4(c) and 5(a)-5(c), 6(a)-6(c); also from tables I and II, increase in the values of $\mathrm{V}_{\mathrm{cm}}, \mathrm{V}_{\mathrm{b}}$ and $\mathrm{I}_{\mathrm{b}}$ is less for $10 \mathrm{HP}$ motor compared to $5 \mathrm{HP}$ motor, due to low impedance of 10HP motor compared to 5HP hence, voltage reflection will be less. The BVR is less for 5-level inverter fed system compared to 3-level inverter fed system with same cable length and HP ratings. It is due to the reduction of dv/dt of inverter output voltage thereby increasing rise time of the pulse.

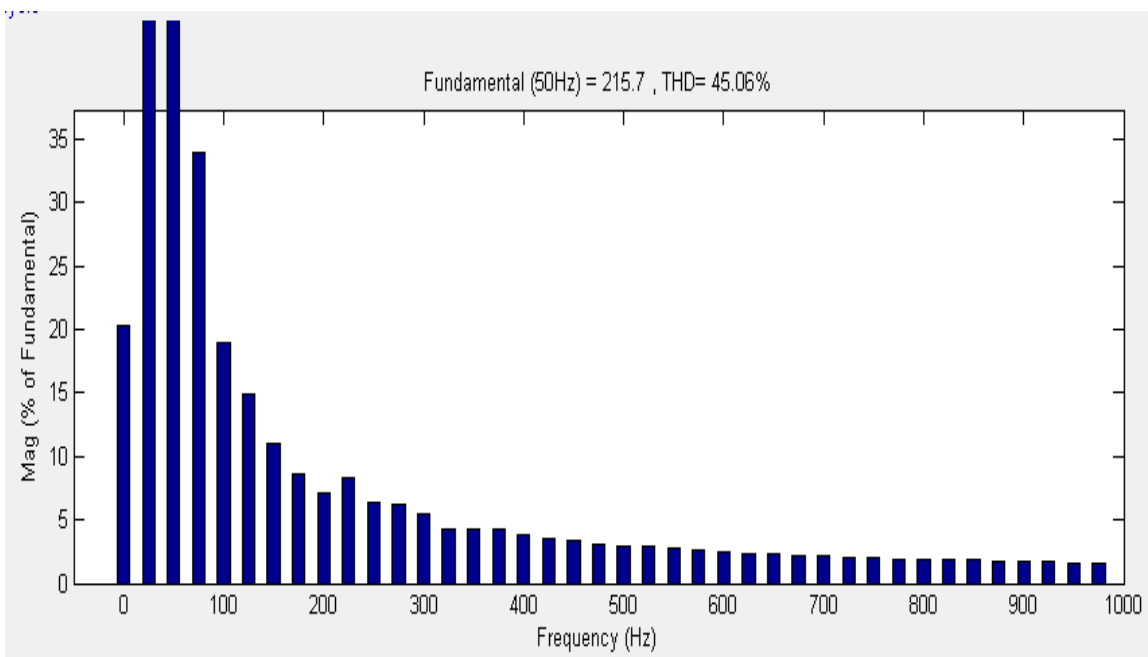

Figure 7 Shows the THD Analysis of line voltage of PWM inverter fed induction motor without long cable (3level 5HP)

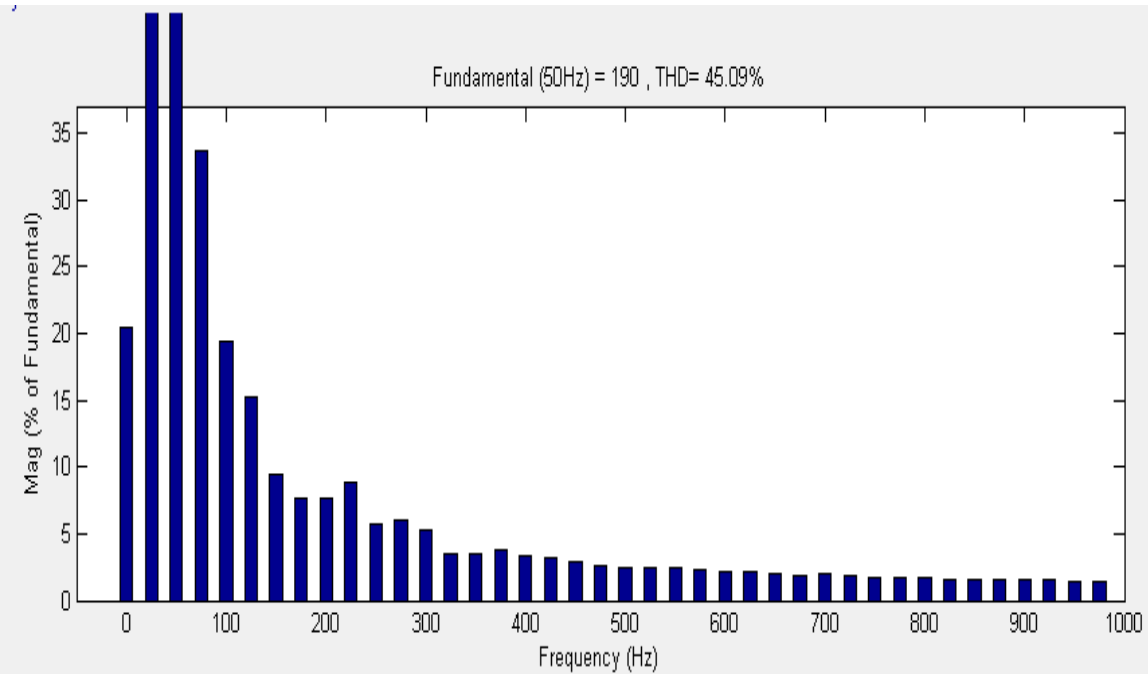

Figure 8 shows the THD Analysis of line voltage of PWM inverter fed induction motor without long cable(3level 10HP) 
Vol. 5, Issue 4, April 2017

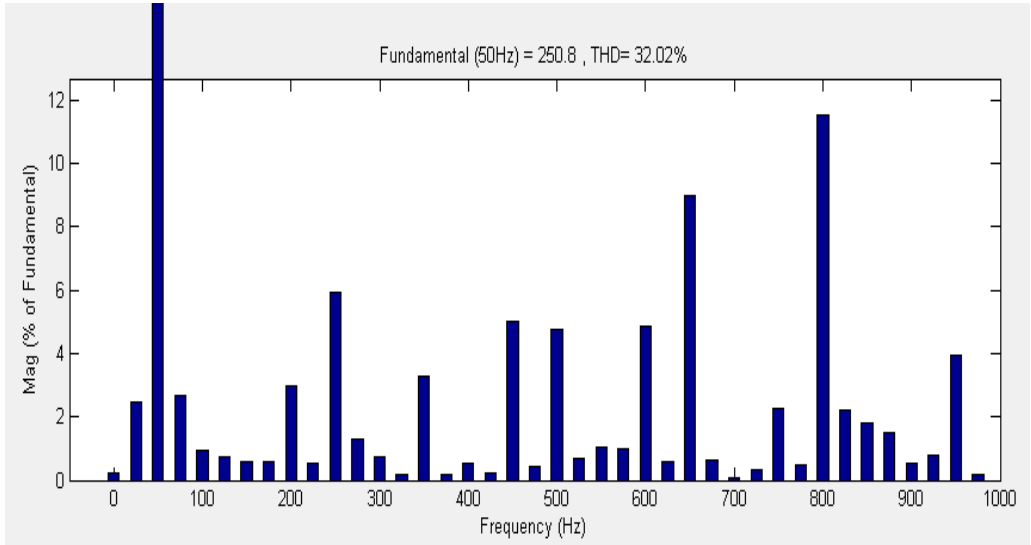

Figure 9 Shows the THD Analysis of PWM Inverter fed induction motor without long cable (5level 5HP)

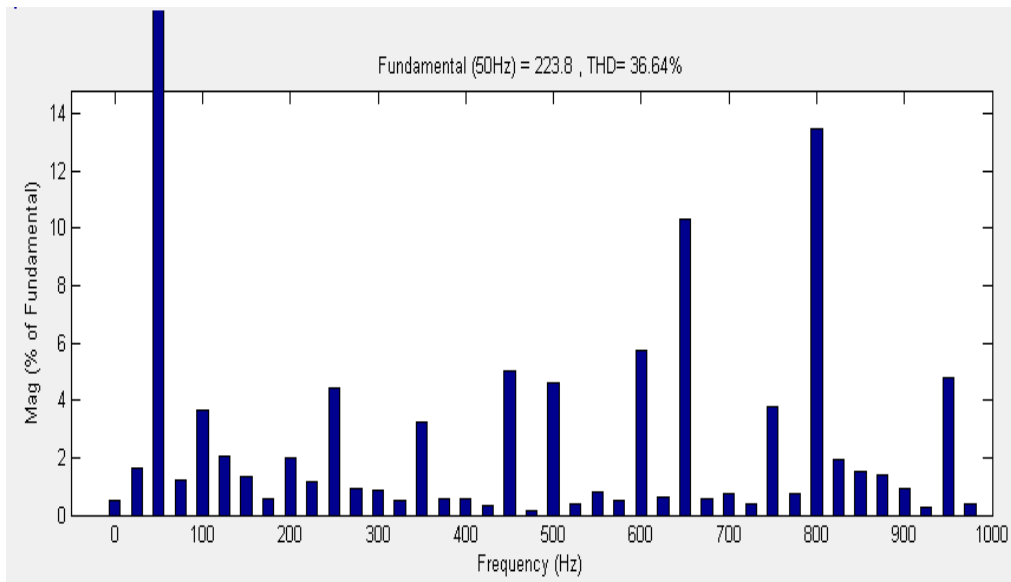

Figure 10 shows the THD analysis of PWM Inverter fed induction motor without long cable. (5level 10HP)

TABLE III SHOWS THE THD ANALYSIS OF PWM MLI WITHOUT LONG CABLE

\begin{tabular}{|l|l|l|}
\hline parameters & THD of 5HP in terms \% & THD of 10HP in terms \% \\
\hline 3 level & 45.06 & 45.09 \\
\hline 5 level & 32.02 & 36.64 \\
\hline
\end{tabular}

\section{CONCLUSION}

In this paper, modelling, simulation and analysis of the common mode voltage, bearing voltage, bearing current and THD Analysis in PWM MLI fed induction motor without the long cable has been carried out. It is observed that, higher the motor HP ratings the magnitude of over voltage at the motor terminal decreases due to impedance matching between the motor and the cable impedance.Hence, reduction in the values of the $V_{c m}, V_{b}$ and $I_{b}$. And it is also observed that as the level of PWM MLI and HP Ratings increases THD reduces.

Information regarding BVR will not be provided on standard induction motor specification .BVR obtained in this paper, helps in predicting the value of $\mathrm{V}_{\mathrm{b}}$, which helps to implement suitable mitigation techniques of bearing current damage. Hence prevents premature bearing failure, reliability of ASD system improved as well as the hidden costs involved in downtime and lost product is avoided.

\section{REFERENCES}

[1] Alger P., Samson H., "Shaft Currents in Electric Machines" A.I.R.E. Conference., Feb. 1924

[2] J. Erdman, R. J. Kerkman, D. Schlegel, and G. Skibinski, "Effect of PWM inverters on AC motor bearing currents and shaft voltages," in IEEE, APEC-95,10th An Applied Power Electronics Conference andExposition, vol. 1, 24 - 33, Mar. 5-9, 1995

[3] Doyle Busse, Jay Erdman, Russel J. Kerkman, Dave Schlegel, and Gary Skibinski "System Electrical Parameters and Their Effects on Bearing Currents", IEEE, transactions, 0-7803-3044-719,1996

[4] Busse, J. M. Erdman, R. J. Kerkman, D. W. Schlegel, and G. L. Skibinski, "Bearing currents and their relationship to PWM drives," in Conf. Record IEEE ,IECON '95, Nov. 1995. 
[5] B. Muralidhar and A.Ramachandran," "Motor Shaft Voltages and Bearing Currents and Their Reduction in Multilevel Medium- Voltage PWM Voltage-Source-Inverter Drive Applications,”. IEEE explore, 2011.

[6] Fei Wang,"Motor Shaft Voltages and Bearing Currents and Their Reduction in Multilevel Medium- Voltage PWM Voltage-Source-Inverter Drive Applications,". IEEE transactions on industry applications, vol. 36, no. 5, pp 1336-1341, September/October 2000.

[7] B.Basavaraja and D.V.S.S.Siva Sarma "Modeling, Simulation and Experimental Analysis of Transient Terminal Overvoltage in PWM-Inverter Fed Induction Motors". Proceedings of International Conference on PES General Meeting held in 333 S. Franklin Street Tampa, Florida,3602 USA, 2007.

[8] Deng wen, LV Chuan, Jiang Jianguo, Huang Lipei and Tamai Shinzo, "Filter design of restraining over-voltage and bearing current ininduction motor,fed by PWM inverter", Proceedings of IEEE TENGONO2,pp 2083-2086.

[9] Ma Hongfei,Xu Dianguo and Miao lijie "Filter Networks for Long Cable Drives and Their Influence onMotor Voltage Distribution and Common-Mode Currents" IEEE explore, PP 1533-1538.

[10] Sharana Reddy and Banakara Basavaraja, "Simulation And Analysis of Common Mode Voltage, Bearing Voltage and Bearing Current in Two Level and Three Level Diode Clamped Multilevel Inverter Fed Induction Motor Drive with Long Cable". IEEE International conference BNMIT-ICPACE, Bangalore, Karnataka, India. Aug12-14, 2015.pp 221-226.

[11] Rudolf Ribeiro Riehl ,Ernesto Rupper t Filho “A Simplified Method for Determining the High Frequency Induction Motor Equivalent Electrical Circuit Parameters to be Used in EMI Effect", Proceeding of International Conference on Electrical Machines and Systems, Seoul, Korea. Oct. 8 11, 2007

[12] F. Moreira T. A. Lipo G. Venkataramanan and S. Bernet "High Frequency Modeling for Cable and Induction MotorOver-voltage Studies in Long Cable Drives.” IEEE Industrial Application Society 36th Annual Meeting Chicago, Illinois, USA, September 30 October 5, 2001 , pp 1-8.

\section{BIOGRAPHIES}

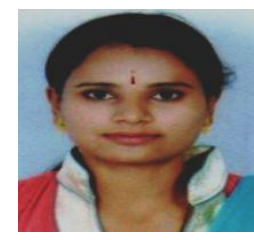

Ms. Sunitha P M, received the B E degree from VTU in 2015 and Pursuing Master Degree in University BDT college of Engineering, Davanegere, a constituent of V.T.U.Belgaum, Karnataka.

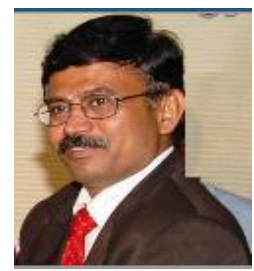

Basavaraja Banakara ME, MBA (HR), Ph.D (NITW), Senior Member EEE,

LMISTE, SMIACSIT, MIAENG, Fellow IEI Executive Committee Member for ISTE Andhra Pradesh Section. He was born in 1970. He obtained his B.E (EEE) degree from Gulbarga University and M.E from Karnataka University, India and he is completed his Doctoral program NIT, Warangal, India. He worked as a Lecturer in VEC Bellary, Associate Professor at SSJ Engineering College Mahaboobnagar, Professor at SR Engineering College Ananthasagar, Waranagal, Principal at Padmasri Dr.BV Raju Institute of Technology, Narasapur, AP, India, Professor \& Director for Academic Registration at KL University, Guntur, AP, India. He also worked as Professor \& Vice-Principal at GITAM University Hyderabad, AP, India. Presently working as Professor and head of the department and BOE chairman in University BDT college of Engineering DavengereKarnataka,India. His areas of interest include power electronics and drives, Power Quality, Micro-grids, High voltage Engineering and EMTP applications. He presented 92 publications in national \& international journals as well as in conferences.

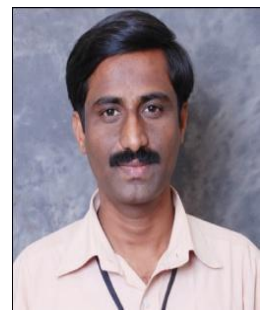

Mr. Sharana Reddy, received the B E degree from Gulbarga University, Gulbarga and M.Tech from V.T.U. Belgaum, Karnataka. Presently working as an Associate professor in BITM, Bellary, and Karnataka. He is IEEE student member. He has guided many undergraduate projects in the field of Power Electronics. His areas of interest include power electronics and Adjustable Speed Drives. At present pursuing Ph D with JNTU, Hyderabad, Andhra Pradesh 